\section{IMPROVING QUALITY OF PRESCRIPTIONS WITH CLINICAL AUDIT}

Sir,

Prescription writing is one of the most important and basic skills that a doctor needs. Specific training and supervision in prescription should be emphasized during undergraduate and postgraduate teaching to minimize related errors. ${ }^{[1]}$ These prescription errors may lead to adverse drug events. The study done to assess adverse drug events by Bates et al. found $28 \%$ of adverse drug events to be preventable in their study and concluded that $56 \%$ of those preventable adverse events occurred at the stage of ordering. ${ }^{[2]}$ Evidence indicates that these adverse drug events are common in long-term psychiatric care units. ${ }^{[3]}$ It may be applicable to other psychiatric settings, although related study has not been reported so far. The use of clinical audit for assessing the nature of prescription errors and establishing standards may be one viable solution for this problem. Clinical audit is shown to be beneficial in many developed countries, especially in the UK, where it is commonly utilized. Often, recommendations from the audit cycle are not effectively implemented or are not pursued completely. ${ }^{[4]}$ This can undermine the utility of clinical audit. A few reports on audit cycles of prescription related to psychiatry have been published in the past few years. ${ }^{[5-7]}$ Even though there is a need for improvement in prescription patterns, ${ }^{[8]}$ we are not aware of such a study conducted in India. This report describes our experience with a systematically conducted audit exercise on prescription orders written by postgraduate resident doctors in psychiatry.

The audit was conducted in the inpatient setting by an adult psychiatry unit of National Institute of Mental Health and Neurosciences, in Bangalore, India in September 2006 and October 2007. It has four general and three special wards, where beds are equally distributed among all six adult psychiatry units. The trainees, following consultant or senior resident rounds, write prescriptions. Initially in this study, standards for prescription orders were defined by obtaining consensus from consultants, senior residents and other treating staff. The demography part of the standards included name, age, sex and income of the patient; name of adult psychiatry unit; hospital registration number; name of the ward; and date of the prescription order. The other part was related to prescription details which consisted of generic name, form and correct spelling of drug; clarity of prescription; emergency orders; review of treatment orders; change of order once advised; and name and signature of the resident. All these needed to be present in every case. The first audit, which was prospective in nature, was done at the end of September 2006 on 24 inpatient records. These records belonged to patients admitted in the same month to the concerned adult psychiatry unit.

Based on the findings and deficits, standards 
were slightly modified in the form of addition of resident's pager number and elimination of patient's income. The feedback was given to the trainees and final standards along with the need for maintaining these standards in the prescription were discussed with them. As in first audit, the $2^{\text {nd }}$ audit was done at the end of October 2007, when records of all inpatients of that month were available. Trainees were told only about the performances in the first audit but were not aware when the audit would be conducted.

While comparing both audits, the findings related to resident's pager number and patient's income were not included as the standards were different for them in two audits. The results showed overall improvement in quality of prescriptions. In the first audit, only $8 \%$ (2 out of 24 ) of prescriptions met all the standards, which increased to $40 \%$ in the second part of the cycle. In the $1^{\text {st }}$ audit, different demographic variables were recorded in different proportions of total prescriptions ranging from 42 to $62.5 \%$ that increased in $2^{\text {nd }}$ audit upto $73 \%$ to 97\% [Table 1].

There was also marked improvement in spelling $(37.5 \rightarrow 53 \%)$ and clarity of drug name $(50 \rightarrow 80 \%)$; review of treatment order $(21 \rightarrow 90 \%)$; and the name of the trainee resident $(8 \rightarrow 90 \%)$ [Table 2]. The pager number of resident was recommended in the discussion following the 1st audit and was found to be entered in $90 \%$ of prescription sheets in 2 nd audit.

In addition, 100\% standards were met for details regarding the titration schedule and the change of treatment orders in the prescription sheet on the same day as ordered during rounds only in $2^{\text {nd }}$ audit [Figure 1]. The standards for
Table 1: Demographic data in prescription orders

\begin{tabular}{lccc}
\hline Variable & Standard & \multicolumn{2}{c}{ Number. Met standard (\%) } \\
\cline { 3 - 4 } & & Audit-1 & Audit-2 \\
\hline Name & 100 & $15(62.5)$ & $26(87)$ \\
Age & 100 & $12(50)$ & $26(87)$ \\
Sex & 100 & $12(50)$ & $26(87)$ \\
Unit & 100 & $14(58)$ & $24(80)$ \\
Reg.No & 100 & $12(50)$ & $24(80)$ \\
Income & 100 & $4(17)$ & Not assessed \\
Ward & 100 & $10(42)$ & $22(73)$ \\
Date & 100 & $24(60)$ & $29(97)$ \\
\hline
\end{tabular}

Table 2: Prescription details in prescription orders

\begin{tabular}{|c|c|c|c|}
\hline \multirow[t]{2}{*}{ Variable } & \multirow[t]{2}{*}{ Standard } & \multicolumn{2}{|c|}{ Number met standard (\%) } \\
\hline & & Audit-1 & Audit-2 \\
\hline \multicolumn{4}{|l|}{ Drug generic } \\
\hline name & 100 & $22(92)$ & $26(87)$ \\
\hline Spellings & 100 & $9(37.5)$ & $16(53)$ \\
\hline Clarity & 100 & $12(50)$ & $24(80)$ \\
\hline Sos orders & 100 & $24(100)$ & $30(100)$ \\
\hline \multicolumn{4}{|l|}{ Orders for } \\
\hline suicidal risk & 100 & $6(100)$ & $7(100)$ \\
\hline Drug form & 100 & $22(92)$ & $29(97)$ \\
\hline \multicolumn{4}{|l|}{$\begin{array}{l}\text { Change of } \\
\text { treatment orders }\end{array}$} \\
\hline (on same day) & 100 & $21(87.5)$ & $30(100)$ \\
\hline $\begin{array}{l}\text { Reviewing } \\
\text { treatment orders } \\
\text { (at least once }\end{array}$ & & & \\
\hline a week) & 80 & $5(21)$ & $27(90)$ \\
\hline $\begin{array}{l}\text { Signature of } \\
\text { resident }\end{array}$ & & 2410 & \\
\hline Name of the & 100 & $24(100)$ & $30(100)$ \\
\hline resident & 100 & $2(8)$ & $27(90)$ \\
\hline Pager no. & 100 & Not assessed & $27(90)$ \\
\hline
\end{tabular}

emergency order, suicidal risk and signature of resident were met in all prescriptions in both audits. There were two variables (date and generic name of the drug), which showed a small decline in the $2^{\text {nd }}$ audit compared to the $1^{\text {st }}$ audit.

This report shows the affect of audit and training of prescription practices in clinical practice. The first audit demonstrated that standards of prescription writing were not being followed adequately in the inpatient psychiatric setting and there was considerable room for improvement. The outcome of $2^{\text {nd }}$ audit was positive, indicating the possibility of improvement with regular, periodic audits. 


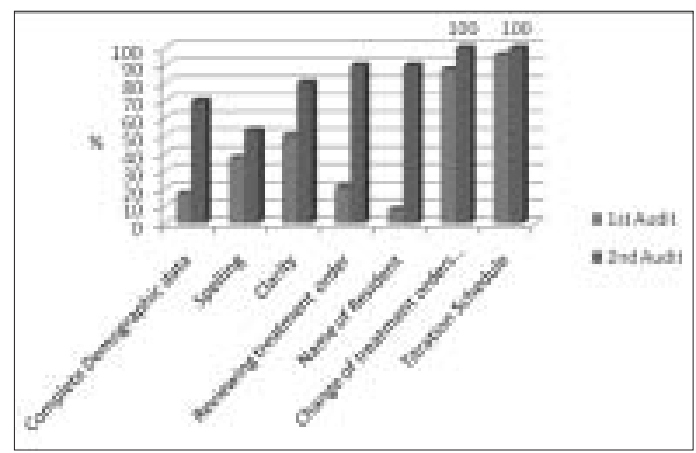

Figure 1: Variables having marked improvement in $2^{\text {nd }}$ Audit

This enhancement was noted in all areas, such as demographic data, drug details as well as the details of the prescribing doctor. The proportion of prescriptions meeting all the standards increased five fold, but was still below $50 \%$, indicating scope for further progress. Nevertheless, this result is better than that observed in prescription-audit related studies in the past. In two different studies at the psychogeriatric unit, only $10 \%{ }^{[6]}$ and $18 \%\left[{ }^{[]]}\right.$ of prescriptions were free of all errors in the $2^{\text {nd }}$ phase of audit cycle.

The legibility as well as correctness of drug spellings needs a special mention, as it decides whether nursing staff is able to identify the drug accurately or not. This is a greater cause of concern in India due to ample availability of similar sounding generic and trade names of entirely different drugs..$^{[9]}$ In a previous study, legibility was 90 percent or above only in all audits of the cycle with improvement in later audits. ${ }^{[5]}$ In the current audit, the clarity of writing was only $50 \%$ in $1^{\text {st }}$ audit which could improve up to $80 \%$ in the $2^{\text {nd }}$ audit. However, the correctness of the spelling of the drug could get better up to $50 \%$ only in the $2^{\text {nd }}$ audit from $37.5 \%$ in the $1^{\text {st }}$ audit. This may need more attention during prescription training. This audit also examined details of the prescription writer (Junior Resident in-charge), which has not been studied in previous prescription audits. It was felt that it is an important part of the order, considering the needs of nursing staff and the ease with which the resident can be contacted regarding any confusion in relation to prescription. We found that it was possible to reach the standard in $90 \%$ of the prescriptions by the $2^{\text {nd }}$ phase.

To conclude, this study demonstrates the possibility of conducting clinical audits in psychiatric and other medical settings in India with the available resources. We were able to successfully conduct the audit in 2 stages by utilizing the existing clinical support and found a positive impact on prescription practices. Though we did it on a small scale, clinical audits can be conducted on other important clinical issues at similar or larger level, which would indicate the relative benefit-cost ratio in a better way and help us in making guidelines for the same.

It is recommended to consider the audit process as a method for improving standards of medical care. Clinical audit can be used in prescription practice, as attempted in this study, as well as various other aspects of clinical services (such as clinical examination, indications for investigation, monitoring side-effects of drug). Finally, this report also emphasizes the benefit of focusing on prescription training in the postgraduate curriculum. There is a need to create more awareness in the trainees towards legibility and correctness of spelling of drug as well as review of treatment and stating the name of prescribing doctor.

\section{ACKNOWLEDGMENT}

Sincere thanks to Senior Residents $\mathrm{Dr}$ 
Bhargavaraman RP, Dr Raghunandan VNGP, Dr. Uzma Mulla, and Dr. Umar Faruk, and all Junior Residents posted during the audit cycle.

\section{S. K. CHATURVEDI, PREETI SINHA, PRABHA S. CHANDRA, GEETHA DESAI Department of Psychiatry, National Institute of Mental Health and Neuro Sciences (NIMHANS), Bangalore-560 029, India \\ Correspondence: \\ S.K. Chaturvedi, Department of Psychiatry, National Institute of Mental Health and Neuro Sciences (NIMHANS), Bangalore-560 029, India. E-mail: skchatur@gmail.com DOI: $10.4103 / 0019-5359.48460$}

\section{REFERENCES}

1. Ferner RE. Medicines management: A sour taste. Q J Med 2002;95:181-4.

2. Bates DW, Cullen D, Laird N, Petersen LA, Small SD, Servi D, et al. Incidence of adverse drug events and potential adverse drug events: Implications for prevention. JAMA 1995;274:29-34.

3. Ito $\mathrm{H}$, Yamazumi S. Common types of medication errors on long-term psychiatric care units. Int J Quality Health Care 2003;15:207-12.

4. Balogh R, Bond S. Completing the audit cycle: The outcomes of audits in mental health services. Int Soc Quality Health Care 2001;13:135-42.

5. Ved P, Coupe T. Improving prescription quality in an in-patient mental health unit: Three cycles of clinical audit. Psychiatr Bull 2007;31:293-4.

6. Onalaja O, Saffrey R, Jones E, Bentham P. Audit of inpatient prescription and. administration records on acute. psychogeriatric wards in a teaching hospital. Psychiatr Bull 2001;25:381-3.

7. Nirodi P, Mitchell AJ. The quality of psychotropic drug prescribing in patients in psychiatric units for the elderly. Aging Ment Health 2002;6:191-6.

8. Patel V, Vaidya R, Naik D, Borker P. Irrational drug use in India: A prescription survey from Goa. J Postgrad Med 2005;51:9-12.

9. Rataboli PV, Garg A. Confusing brand names: Nightmare of medical profession. J Postgrad Med 2005;51:13-6.

\section{Author Help: Reference checking facility}

The manuscript system (ww w.journalonw eb.com) allows the authors to check and verify the accuracy and style of references. The tool checks the references with PubMed as per a predefined style. Authors are encouraged to use this facility, before submitting articles to the journal.

- The style as well as bibliographic elements should be $100 \%$ accurate, to help get the references verified from the system. Even a single spelling error or addition of issue number/month of publication will lead to an error when verifying the reference.

- Example of a correct style

Sheahan P, O'leary G, Lee G, Fitzgibbon J . Cystic cervical metastases: Incidence and diagnosis using fine needle aspiration biopsy. Otolaryngol Head Neck Surg 2002;127:294-8.

- $\quad$ Only the references from journals indexed in PubM ed will be checked.

- $\quad$ Enter each reference in new line, without a serial number.

- Add up to a maximum of 15 references at a time.

- If the reference is correct for its bibliographic elements and punctuations, it will be show $n$ as CORRECT and a link to the correct article in PubM ed will be given.

- If any of the bibliographic elements are missing, incorrect or extra (such as issue number), it will be show $n$ as INCORRECT and link to possible articles in PubM ed will be given. 